\title{
Frequência de anticorpos para paratuberculose em bovinos no semiarido paraíbano ${ }^{1}$
}

\author{
João Marcos de Araújo Medeiros², Felício Garino Junior², Rodrigo Antonio Torres \\ Matos $^{2}$, Valeria Maria de Medeiros Costa $^{2}$ e Franklin Riet-Correa ${ }^{2 *}$
}

\begin{abstract}
Medeiros J.M.A., Garino Jr F., Matos R.A.T., Costa V.M.M. \& Riet-Correa F. 2012. [Frequency of antibodies against paratuberculosis in cattle in the state of Paraiba.] Frequência de anticorpos para paratuberculose em bovinos no estado da Paraíba. Pesquisa Veterinária Brasileira 32(8):697-700. Hospital Veterinário, Centro de Saúde e Tecnologia Rural, Campus de Patos, Universidade Federal de Campina Grande, Patos, PB 58700-000, Brasil.E-mail: franklin.riet@pq.cnpq.br

Paratuberculosis is an important disease of cattle in the state of Paraíba, northeastern Brazil. In the Veterinary Hospital of the Federal University of Campina Grande, five outbreaks of paratuberculosis were diagnosed in the last four years. The objective of this paper is to report the frequency of antibodies against paratuberculosis in different regions of the state of Paraíba, in farms with previous diagnosis of the disease and in farms without diagnosis. The prevalence of antibodies against paratuberculosis, examined by ELISA, in two farms with cases of the disease, was of $72.22 \%(13 / 18)$ and $68.75 \%(11 / 16)$, respectively. Serum samples from 486 healthy cattle from 36 farms without paratuberculosis diagnosis, from three different regions of Paraíba (sertão, cariri, and agreste), were also examined by ELISA. The frequency of antibodies was $10.08 \pm 1,07 \%$ (49/486). Antibodies against paratuberculosis were found in 21 (58.33\%) out of 36 farms examined. These results suggest that paratuberculosis is an important disease of cattle in the state of Paraíba and that control measures to decrease the prevalence of the disease are necessary.
\end{abstract}

INDEX TERMS: Mycobacterium avium subsp. paratuberculosis, paratuberculosis, cattle, ELISA, northeastern Brazil.

RESUMO.- A paratuberculose é uma doença importante em bovinos na Paraíba, tendo sido diagnosticados, pelo Hospital Veterinário da Universidade Federal de Campina Grande, cinco focos da doença nos últimos quatro anos. Neste trabalho objetivou-se realizar um estudo sorológico em rebanhos com e sem histórico da doença para estimar a frequência da infecção por Mycobacterium avium subsp. paratuberculosis (Map) em diferentes regiões do semiárido Paraibano. Utilizando o teste de ELISA pesquisou-se a frequência de animais soropositivos contra Map em duas fazendas onde tinha sido diagnosticada a doença, encontrando-se 72,22\% (13/18) e 68,75\% (11/16), respectivamente de bovinos sorologicamente positivos. Amostras de soro de 486 bovinos de 36 fazendas sem histórico da doença de diferentes regiões da Paraíba (sertão, cariri

\footnotetext{
${ }^{1}$ Recebido em 27 de junho de 2011.

Aceito para publicação em 10 de março de 2012.

${ }^{2}$ Hospital Veterinário, Centro de Saúde e Tecnologia Rural (CSTR), Campus de Patos, Universidade Federal de Campina Grande, Patos, PB 58700000, Brasil. *Autor para correspondência: franklin.riet@pq.cnpq.br
}

e agreste), também foram examinados por ELISA. A frequência de animais soropositivos foi de 10,08 $\pm 1,07 \%$ (49/486). Foram encontrados animais positivos em 21 (58.33\%) das 36 fazendas estudadas. Os resultados sugerem que o agente da paratuberculose está disseminado em bovinos na Paraíba e que são necessárias medidas de controle para diminuir a frequência de casos clínicos e subclínicos da doença.

TERMOS DE INDEXAÇÃO: Mycobacterium avium subsp paratuberculosis, paratuberculose, bovinos, ELISA, semiárido brasileiro.

\section{INTRODUÇÃO}

A paratuberculose ou Doença de Johne é uma enfermidade infecciosa crônica, incurável e de distribuição mundial. Afeta bovinos, caprinos, ovinos, bubalinos e ruminantes selvagens, mas também acomete com menor frequência, suínos, lebres e eqüinos. 0 agente etiológico é o Mycobacterium avium subsp. paratuberculosis (Map) que causa enterite e linfadenite granulomatosas (Clarke 1997, Harris \& Barletta 2001, Riet-Correa \& Driemeier 2007, Moravkova et al. 
2008). É uma doença que acarreta consideráveis perdas econômicas. Nos EUA o prejuízo anual para indústria leiteira, devido à paratuberculose bovina, é da ordem de 200 a 250 milhões de dólares (Ott et al. 1999). Essas perdas devem-se a diminuição da produção, descarte prematuro dos animais, maior susceptibilidade a outras doenças, redução na fertilidade e aumento nos custos sanitários (Losinger 2005). Além da importância da paratuberculose como causa de perdas econômicas em ruminantes, há indícios de que o M. avium subesp. paratuberculosis seja o agente casual da ileocolite granulomatosa em humanos conhecida como doença de Crohn (Chiodini \& Rossiter 1996).

Em ruminantes, a infecção geralmente ocorre logo após o nascimento mediante ingestão de colostro ou leite de animais infectados e água e alimentos contaminados de fezes de animais infectados (Clarke \& Little 1996). Há também transmissão pela via intra-uterina (Radostits et al. 2007). 0 diagnóstico laboratorial pode ser realizado pelo isolamento de M. avium subesp. paratuberculosis das fezes ou material de necropsia e por estudo histológico das lesões. Em esfregaços de fezes e de raspados das porções finais do intestino delgado corados pelo Ziehl-Neelsen observam-se bactérias álcool-ácido resistentes. 0 diagnóstico dos casos subclínicos pode ser realizado por isolamento do micro-organismo em fezes ou leite, provas sorológicas para detecção rápida de animais infectados (fixação de complemento, imunodifusão em agar gel e ELISA), detecção de gamma interferon, PCR ou testes alérgicos (Riet-Correa \& Driemeier 2007).

Tanto o isolamento quanto o teste alérgico e as provas sorológicas são eficientes para determinar rebanhos infectados, mas não apresentam suficiente acurácia para o diagnóstico individual (Riet-Correa \& Driemeier 2007). A tuberculinização é realizada com tuberculina produzida com M. avium subesp. paratuberculosis ou com M. avium. Ocorrem reações cruzadas com a tuberculose bovina, razão pela qual em rebanhos com esta doença deve-se realizar a prova comparativa (Riet-Correa \& Driemeier 2007).

No Brasil há relatos da paratuberculose em bovinos em diversos Estados das regiões Sul e Sudeste (Portugal et al. 1979, Ramos et al. 1986, Driemeier et al. 1999, Gomes et al. 2002). Recentemente a doença foi diagnosticada, também, em bovinos (Mota et al. 2007, Motta et al. 2009) e bubalinos (Mota et al. 2010) na região nordeste do Brasil. Na Paraíba a paratuberculose foi diagnosticada em bovinos (Motta et al. 2009) e em ovinos e caprinos (Oliveira et al. 2010). Neste Estado, a doença tem sido observada frequentemente em bovinos, tendo sido diagnosticados, pelo Hospital Veterinário da UFCG, cinco focos de paratuberculose nos anos de 2008 a 2011 (dados não publicados).

Objetivou-se com esta pesquisa realizar um estudo sorológico em rebanhos onde ocorreram casos da doença e em rebanhos sem histórico da doença para estimar a frequência da infecção por Map em diferentes regiões do semiárido paraibano.

\section{MATERIAL E MÉTODOS}

Para o estudo da frequência de anticorpos contra o Map foram coletadas amostras de soro de todos os bovinos (34) em duas fazendas com diagnóstico de paratuberculose, uma no municí- pio de São Momede e outra no Município de Patos. Além disso, foram coletadas 486 amostras de 36 propriedades sendo quatro do Agreste, oito do Cariri e 24 do Sertão, totalizando 520 animais. 0 número de amostras dependeu da disponibilidade do produtor para a coleta, mas em todas as propriedades foi coletado sangue de, aproximadamente $10 \%$ dos bovinos existentes. Para a determinação de anticorpos para paratuberculose nos animais das 38 propriedades foi utilizada a técnica de ELISA. Os animais estudados eram das raças Gir, Holandês, Girolando, e seus cruzamentos, assintomáticos, com idade variando entre 4 meses a 13 anos. Foram coletados de cada animal $10 \mathrm{ml}$ de sangue por venopunção da jugular externa através de agulhas acopladas a tubos a vácuo. As amostras de sangue foram centrifugadas a $1700 \mathrm{x}$ g por $15 \mathrm{minu}-$ tos e os soros transferidos para três tubos de Eppendorf de $3 \mathrm{ml}$, mantidos a $-70^{\circ} \mathrm{C}$, e posteriormente, testadas mediante o teste de ELISA adsorvido. Para a pesquisa de anticorpos Anti-Mycobacterium avium subesp. paratuberculosis foi utilizado kit comercial (ID SCREEN®, Paratuberculosis Indirect ${ }^{3}$. A leitura das amostras de soro foi realizada por uma Leitora de microplaca ${ }^{4}$ ). Para a interpretação dos resultados dos animais positivos e negativos no teste foi considerado um ponto de corte acima de $70 \%$, conforme o manual do fabricante.

As análises estatísticas foram realizadas por meio do teste de Qui-quadrado com correção de Yates e o nível de significância adotado foi de $5 \%$. Os dados foram analisados estatisticamente utilizando o programa GRAPHPAD INSTAT versão 3.00 para Windows 95, GraphPad Software.

\section{RESULTADOS}

Na Fazendas A e B realizou-se estudo sorológico em todos os bovinos da propriedade e as frequências foram de $68,75 \%(11 / 16)$ e $72,22 \%$ (13/18), respectivamente.

Nas 36 fazendas sem histórico clínico de paratuberculose a frequência foi de 10,08 $\pm 1,07 \%$ (49/486) (Quadro 1). Não foram encontradas diferenças estatísticas entre as frequências observadas nas três regiões estudadas $(P>0,05)$. No Sertão, a frequência foi de $10 \%(32 / 320)$ com intervalo de confiança de 6,94-13,82\%, no Agreste 11,11\% (9/81) com intervalo de confiança de 5,21-20,05\% e no Cariri foi de 9,41\% (8/85) com intervalo de confiança de 4,15$17,71 \%$. Os resultados da frequência em cada propriedade são apresentadas no Quadro 1.

\section{DISCUSSÃO}

0 diagnóstico da enfermidade em diversas fazendas da Paraíba, a alta frequência de anticorpos $(70,6 \%)$ em duas fazendas onde ocorreram casos clínicos de paratuberculose, e a presença de anticorpos em 21 de 36 fazendas sem histórico da doença, que apresentaram uma frequência média de $10,08 \%$, sugere que o Map está disseminado nas três regiões estudadas do estado da Paraíba. Em outros países a prevalência de anticorpos é variável; nos Estados Unidos e Canadá varia de $4,73 \%$ a $18 \%$ (Pence et al 2003, Sorensen et al. 2003, Paolicchi 2004), na Austrália de $9 \%$ a $22 \%$ e na Argentina, na província de Buenos Aires, de 7,2\% a 19,6\% (Paolicchi 2004). Nos Estados Unidos estima-se que a paratuberculose ocasiona perdas anuais de 1500 milhões de

\footnotetext{
${ }^{3}$ ID Screen ${ }^{\circledR}$ Paratuberculosis Indirect - ID Vet Inovative Diagnostics, Montepelle, France.

${ }^{4}$ Thermo Plate Tp - Reader®.
} 


\section{Quadro1. Resultados dos testes de ELISA, para detecção de anticorpos contra Mycobacterium avium subesp. paratuberculosis em 486 amostras de bovinos em 36 propriedades, sem histórico clínico de paratuberculose, de 11 municípios do semiárido Paraibano}

\begin{tabular}{|c|c|c|c|c|}
\hline Fazenda/município/ Região & Total & Testados & Positivos & $\%$ \\
\hline 1/Patos/sertão & 65 & 8 & 5 & 62,5 \\
\hline 2/Patos/sertão & 17 & 17 & 0 & 0,0 \\
\hline 3/Patos/sertão & 25 & 10 & 0 & 0,0 \\
\hline 4/Patos/sertão & 44 & 22 & 0 & 0,0 \\
\hline 5/Patos/sertão & 22 & 10 & 2 & 20,0 \\
\hline 6/Patos/sertão & 50 & 9 & 0 & 0,0 \\
\hline 7/Piancó/sertão & 26 & 9 & 1 & 11,11 \\
\hline 8/Piancó/sertão & 15 & 7 & 1 & 14,29 \\
\hline 9/Piancó/sertão & 25 & 15 & 2 & 13,33 \\
\hline 10/Piancó/sertão & 28 & 9 & 1 & 11,11 \\
\hline 11/Piancó/sertão & 15 & 5 & 0 & 0,0 \\
\hline 12/ Piancó/sertão & 160 & 15 & 1 & 6,66 \\
\hline 13/Piancó/sertão & 180 & 15 & 2 & 13,33 \\
\hline 14/ Piancó/sertão & 20 & 9 & 0 & 0,0 \\
\hline 15/ Piancó/sertão & 57 & 15 & 1 & 6,66 \\
\hline 16/ Piancó/sertão & 8 & 5 & 0 & 0,0 \\
\hline 17/Piancó/sertão & 120 & 20 & 2 & 10 \\
\hline 18/Nova Olinda/sertão & 100 & 18 & 3 & 16,66 \\
\hline 19/Santa Terezinha/sertão & 45 & 19 & 8 & 42,10 \\
\hline 20/São J. Espinharas/sertão & 100 & 24 & 1 & 4,16 \\
\hline 21/São J. Bonfim/sertão & 18 & 18 & 1 & 5,55 \\
\hline 22/Santa Gertrudes/sertão & 80 & 10 & 1 & 10,0 \\
\hline 23/São Gonçalo/sertão & 84 & 16 & 0 & 0 \\
\hline 24/São Gonçalo/sertão & 25 & 15 & 0 & 0 \\
\hline 25/Bananeiras/agreste & 28 & 11 & 0 & 0,0 \\
\hline 26/Bananeiras/agreste & 30 & 25 & 1 & 4,0 \\
\hline 27/Campina Grande/agreste & 105 & 30 & 7 & 23,33 \\
\hline 28/Bananeiras/agreste & 58 & 15 & 1 & 6,66 \\
\hline 29/Boa Vista/cariri & 100 & 14 & 0 & 0,0 \\
\hline 30/Boa Vista/cariri & 120 & 19 & 2 & 10,52 \\
\hline 31/Boa Vista/cariri & 30 & 9 & 0 & 0,0 \\
\hline 32/Boa Vista/cariri & 25 & 5 & 1 & 20,00 \\
\hline 33/Boa Vista/cariri & 28 & 5 & 0 & 0,0 \\
\hline 34/Boa Vista/cariri & 52 & 5 & 0 & 0,0 \\
\hline 35/Boa Vista/cariri & 50 & 14 & 4 & 28,57 \\
\hline 36/Cabaceiras/cariri & 80 & 14 & 1 & 7,14 \\
\hline TOTAL & 2035 & 486 & 49 & 10,08 \\
\hline
\end{tabular}

dólares e que a indústria leiteira perde de 200 a 250 milhões de dólares por ano (Stabel 1998, Paolicchi 2004). No Canadá, as perdas econômicas são estimadas em 15 milhões de dólares por ano na indústria leiteira (Mckenna et al. 2006). Na Austrália estima-se que as perdas econômicas anuais são de 2,4 milhões de dólares, na Nova Zelândia 8,8 milhões de dólares/ano e na Holanda 42,5 milhões de dólares/ano (Kennedy \& Benedictus 2001). No Brasil, em fazendas sem casos clínicos foram encontradas prevalências ainda maiores que as observadas na Paraíba, de $18 \%$ no Rio de Janeiro (Ferreira et al. 2001) e 39,8\% no Rio Grande do Sul (Gomes 2002). Em Pernambuco em uma fazenda com casos clínicos de paratuberculose a prevalência de anticorpos foi de 32,8\% (Mota et al. 2007).

Todos esses dados, avaliados no seu conjunto, sugerem que a paratuberculose é uma doença que causa perdas econômicas importantes na Paraíba e no Brasil. Em pequenos ruminantes, na Paraíba, foi encontrada uma alta frequência de anticorpos para paratuberculose, sendo $48,3 \%$ em caprinos e 50,63\% em ovinos (Medeiros et al. 2011). Os autores sugerem que a alta frequência deve-se ao confinamento ou semi-confinamento em condições higiênicas que favorecem a transmissão da enfermidade (Medeiros et al. 2011). É evidente a necessidade de realizar maiores investigações para verificar o impacto econômico da doença, os fatores de risco e as medidas de controle mais adequadas para as diferentes regiões.

Agradecimentos.- 0 primeiro autor agradece ao CNPq pela concessão da bolsa do Mestrado. Este trabalho foi financiado pelo CNPq (Proc. 471783/2008-0).

\section{REFERÊNCIAS}

Chiodini R.J. \& Rossiter C.A. 1996. Paratuberculosis a potencial zoonosis, Vet. Clin. North Am., Food Anim. Pract. 12(2):457-467.

Clarke C.J. \& Little D. 1996. The pathology of ovine paratuberculosis: Gross and histological changes in the intestine and other tissues. J. Comp. Pathol. 114(4):419-437.

Clarke C.J. 1997. The pathology and pathogenesis of paratuberculosis in ruminants and other species: A review. J. Comp. Pathol. 116(3):217-261.

Driemeier D., Cruz C.E.F., Gomes M.J.P., Cordellini G.L., Loretti A.P. \& Colodel E.M. 1999. Aspectos clínicos e patológicos da paratuberculose em bovinos no Rio Grande do Sul. Pesq. Vet. Bras. 19(3/4):109-115.

Ferreira R., Fonseca L.S. \& Lilenbaum W. 2001. Detecção de Anticorpos contra o Mycobacterium paratuberculosis em rebanhos bovinos do estado do Rio de Janeiro, Brasil. Revta Bras. Med. Vet. 23:166-171.

Gomes M.J.P. 2002. Paratuberculose bovina: um grande desafio sanitário brasileiro. Minas de Leite 3(24):19-21.

Harris N.B. \& Barletta R.G. 2001. Mycobacterium avium subsp. paratuberculosis in veterinary medicine. Clin. Microbiol. 14(3):489-512.

Kennedy D.J. \& Benedictus G. 2001. Control of Mycobacterium avium subsp. paratuberculosis infection in agricultural species. Rev. Sci. Tech. Int. Epiz. 20(1):151-179.

Losinger W.C. 2005. Economic impact of reduced milk production associated with Johne's diasease on dairy operations in the USA. J. Dairy Res. 72(4):425-432.

Mckenna S.L., Keefe G.P., Tiwari A., Vanleeuwen J. \& Barkerma H.W. 2006. Johne's disease in Canada part II: Disease impacts, risk factors, and control programs for dairy producers. Can. Vet. J. 47(11):1089-1099.

Medeiros J.M.A., Garino Jr F., Almeida A.P., Lucena E.A. \& Riet-Correa F. 2012. Paratuberculose em caprinos e ovinos no Estado da Paraíba. Pesq. Vet. Bras. 32(2):111-115.

Moravkova M., Hlozek P., Beran V., Pavlik I., Preziuso S., Cuteri V. \& Bartos M. 2008. Strategy for the detection and differentiation of Mycobacterium avium species in isolates and heavily infected tissues. Res. Vet. Sci. 85(2):257-264.

Mota R.A., Pinheiro Junior J.W., Gomes M.J.P., Peixoto R.M., Maia F.C.L., Brito M.F., Chies J.A.B., Snel G.G.M., Bercht B.S. \& Juffo G.D. 2007. Paratuberculose em um rebanho bovino leiteiro no estado de Pernambuco. Arqs Inst. Biológico, São Paulo, 74(2):73-79.

Mota R.A., Peixoto P.V., Yamasaki E.M., Medeiros E.S., Costa M.M., Peixoto R.M. \& Brito M.F. 2010. Ocorrência de paratuberculose em búfalos (Bubalus bubalis) em Pernambuco. Pesq. Vet. Bras. 30(3):237-242.

Motta P., Mota P.C., Pires P.S., Assis R.A., Salvarani F.M., Leite R.M.H., Dias L.D., Leite R.C., Lobato F.C.F., Guedes R.M.C. \& Lage A.P. 2009. Paratuberculose em um rebanho Gir leiteiro no Estado da Paraíba Brasil. Pesq. Vet. Bras. 29(9):703-706.

Oliveira D.M., Riet-Correa F., Galiza G.J.N., Assis A.C.O., Dantas A.F.M., Bandarra P.M. \& Garino Jr F. 2010. Paratuberculose em caprinos e ovinos no Brasil. Pesq. Vet. Bras. 30(1):67-72.

Ott S.L., Wells S.L. \& Wagner B.A. 1999. Herd-level economic losses associated with Johne's disease on US dairy operations. Prev. Vet. Med. 40(3/4):179-192.

Paolicchii F. 2004. Paratuberculosis: aspectos clínicos patológicos y su impacto em la producción. XXXII Jornadas Uruguayas de Buiatría, Paysandú, Uruguay, p.127-131. 
Pence M., Baldwin C. \& Carter Black III, C. 2003. The seroprevalence of Johne's disease in Georgia beef and dairy cull cattle. J. Vet. Diagn. Invest. 15:475-477.

Portugal M.A.S.C., Pimentel J.N., Saliba A.M., Baldassi L. \& Sandoval E.F.D. 1979. Ocorrencia de paratuberculose no estado de Santa Catarina. O Biológico, São Paulo, 45:19-24.

Radostits O.M., Gay C.C., Hinchcliff K.W. \& Constable P.T. 2007. Veterinary Medicine. $10^{\text {th }}$ ed. Saunders, Elsevier, Edinburgh, p.1017-1044.

Ramos E.T., Poster F.P., Correia B.L., De Oliveira S.J., Rodrigues N.C. \& Cana- barro C.E. 1986. Paratuberculose em bovinos no estado do Rio Grande do Sul. Hora Vet. 6(34):28-32.

Riet-Correa F. \& Driemeier D. 2007. Paratuberculose, p.407-414. In: Riet-Correa F., Schild A.L., Lemos R.A.A. \& Borges J.R.J. (Eds), Doenças de Ruminantes e Eqüinos. Vol.1. 3a ed. Pallotti, Santa Maria, RS.

Stabel J.R. 1998. Johnes disease a hidden treat. J. Dairy Sci. 81:283-288.

Sorensen O., Rawluk S., Wu J., Manninen K. \& Ollis G. 2003. Mycobacterium paratuberculosis in dairy herds in Alberta. Can. Vet. J. 44:221226. 